\title{
Práticas da Psicologia no Campo da Justiça, do Trabalho e da Educação
}

\section{Practices of Psychology in the Felds of Justice, Work and Education}

\section{Prácticas de la Psicología en el Campo de la Justicia, Trabajo y Educación}

\author{
Neuza Maria de Fátima Guareschi \\ Universidade Federal do Rio Grande do Sul, Porto Alegre, RS, Brasil.
}

É com grande satisfação que anunciamos que a partir desta edição da Revista Psicologia: Ciência e Profissão passa a contar com a colaboração da nova comissão editorial para o triênio 2017-2019, composta por cinco colegas. Agora, juntamente com a editora e editor associado, formamos um grupo de sete pessoas trabalhando neste periódico, além da nossa assessoria no trabalho da secretaria e da comunicação.

As publicações que apresentamos neste editorial da edição 37.3 estão relacionadas a algumas áreas de atuação do profissional da Psicologia mais tradicionais como o campo jurídico, o escolar e o do trabalho mais especificamente. Dos 20 trabalhos que estão sendo publicados, cinco deles remetem ao trabalho do psicólogo no campo jurídico que discutem as práticas de Psicologia em alguns setores do sistema judicial ou que pesquisam sobre atividades do campo jurídico ou de trabalhadores da área de segurança pública. Relacionados ao campo da escola também são cinco trabalhos apresentando pesquisas de temas da educação com jovens e professores. No campo da Psicologia de Trabalho, temos três artigos sobre doença do trabalho, o trabalho para pessoas deficientes e o trabalho de acompanhamento terapêutico de profissionais da saúde. Além destas 13 publicações, apresentamos também neste editorial seis artigos teóricos que discutem conceitos de diferentes áreas da Psicologia e, para fechar a edição, mais um relato de experiência.

Sabemos que a Psicologia surge como ciência, principalmente, para trabalhar com pessoas cujos comportamentos não correspondiam às expectativas das demandas institucionais (Rose, 2008). Era no intuito de atender solicitações de instituições como fábricas, escolas, prisões, hospitais entre outras que a Psicologia, inicialmente, emergiu como um saber para analisar condutas que não se adaptavam ao padrão de comportamentos estabelecidos por normas institucionais (Medeiros, \& Bernardes, 2005). Entretanto, apesar deste foco teórico inicial ser voltado para estudos para adaptação e condução de condutas, os saberes da Psicologia também foram se constituindo em uma ferramenta potente de crítica sobre as formas de governo, colocando em análise práticas de construção de verdades que nos subjetivam (Scisleski, 2010). Assim, na contemporaneidade, os saberes da Psicologia possibilitam outros modos de pesquisa e gestão de ações e intervenções para a maximização da vida. Talvez, como uma Psicologia bergsoniana, possamos desafiar os modos de produzir conhecimento e, assim, passar a provocar reações aos olhares do pensar natural das instituições em que a Psicologia desenvolve suas práticas (Bergson, 1974).

Neste número da Revista "Psicologia: Ciência e Profissão", os cinco artigos que tratam de pesquisas sobre a Psicologia relacionadas com a área judicial dizem respeito aos contextos da justiça restaurativa, do juizado da infância, do trabalho da polícia militar, das medidas socioeducativas e do depoimento sem danos. O primeiro destes artigos, "A Polícia e suas Polícias: Clientela, Hierarquia, Soldado e Bandido", de Erika Ferreira de Azevedo, buscou estudar os efeitos de reconhecimento e desconhecimento das relações no trabalho que permeiam o discurso de soldados da polícia militar, ou seja, como estes falam de seu trabalho e, através desta fala, como se posicionam e posicionam sua clientela, sua hierarquia, seu objeto de trabalho e eles próprios. A partir das análises que realizou, indica ser possível para estes trabalhadores da segu- 
rança pública refletir sobre a dubiedade do verdadeiro objetivo do trabalho policial, deslizando facilmente do cuidado da população desamparada ao cuidado de si, desamparado sob a pressão da farda.

Os próximos três artigos dentro desta área do sistema judicial possuem em comum a pesquisa com adolescentes. $\mathrm{O}$ primeiro deles analisou a magnitude $\mathrm{e}$ a tendência da mortalidade por homicídios ocorridos no estado de Pernambuco, Brasil, no período de 2009 a 2014. O artigo intitulado "Análise dos Homicídios em Pernambuco e as Contribuições da Justiça Restaurativa", de Nemésio Dario Vieira de Almeida, indica que nesse período dos 20.891 óbitos por homicídios em Pernambuco $56,1 \%$ deles ocorreram no grupo de 15 a 29 anos de idade. $O$ texto aponta ser ainda difícil de avaliar possíveis resultados e impactos do trabalho da Justiça Restaurativa para esta população por ser algo novo e por não ter sido originalmente um modelo criado no cenário brasileiro. O segundo artigo, "Adolescência e Ato Infracional: Violência Institucional e Subjetividade em Foco", de Cinthya Rebecca Santos Azevedo, Tâmara Ramalho de Sousa Amorim e Maria de Fatima Pereira Alberto, analisou as implicações da violência institucional na subjetividade de adolescentes em cumprimento de medidas socioeducativas em meio aberto na cidade de João Pessoa, PB. Os resultados indicaram que todos os adolescentes sofreram violência institucional que produziu assujeitamentos expressos na resignação, na desvalorização de si e no medo, promovendo o ajuste subjetivo do adolescente. Alguns, entretanto, apresentaram resistências a esses assujeitamentos, que emergiram ligadas à garantia de direitos e foram representadas por um aumento da autoestima, motivação, confiança e pela construção de um projeto de vida. Já o terceiro artigo sobre pesquisa com adolescentes, "O Depoimento Judicial de Crianças e Adolescentes entre Apoio e Inquirição", de Adriana Ribeiro dos Santos e José César Coimbra, teve como objetivo verificar se haveria correspondência entre as práticas de depoimento judicial de crianças e adolescentes no Brasil e as diretrizes estabelecidas na Resolução no 20/2005 do United Nations Economic and Social Council - Ecosoc e eventuais diferenças entre as práticas nacionais e a referência internacional escolhida, em particular no que se relaciona aos papéis do intermediário e da pessoa de confiança. Constataram que o protocolo do Tribunal de Justiça do Estado de São Paulo revela mais pontos em comum com a Resolução Ecosoc n ${ }^{\circ}$ 20/2005 do que com o do Rio de Janeiro, observando a inexistência de previsão da pessoa de confiança no protocolo do Rio de Janeiro. O papel do intermediário é definido em ambos os protocolos, à diferença da pessoa de confiança. Experiências internacionais apontam que a pessoa de confiança é fator de sucesso na proteção da criança.

O último destes cinco artigos relacionados à área judicial trata da temática sobre processos de adoção. O artigo "A Equipe Psicossocial na Colocação da Criança nos Processos de Adoção", de Patrícia Santos da Silva, Luciana Cassarino-Perez, Jorge Castellá Sarriera e Giana Bitencourt Frizzo, objetivou investigar e refletir sobre o papel da equipe psicossocial do Judiciário na fase de inserção, ou, em termos legais, colocação, nos processos de adoção. Foram entrevistados sete psicólogos e 11 assistentes sociais judiciários de sete cidades do Rio Grande do Sul onde foi possível constatar diferenças entre as práticas dos profissionais, ficando os psicólogos mais encarregados dos processos considerados complexos, a exemplo dos casos de adoção tardia.

Os três relacionados à área de trabalho tratam de pesquisas com temas bem diferenciados do trabalho da Psicologia neste campo. O primeiro deles, o artigo "O Diagnóstico de LER e os Sintomas de DORT: Estudo com Bancários”, de Paulo Wenderson Moraes e Antonio Virgílio Bittencout Bastos, teve como objetivo comparar os sintomas osteomusculares entre os bancários que afirmaram já terem sido diagnosticados por LER/DORT, com aqueles que afirmaram nunca terem sido diagnosticados por algum médico. Um dos resultados que o estudo aponta é que os que possuem diagnóstico de LER/DORT são os que mais sentem sintomas osteomusculares. $\mathrm{O}$ segundo artigo trata atuação do psicólogo organizacional e do trabalho na inclusão de pessoas com deficiência no mercado de trabalho.

O segundo artigo versa sobre o trabalho do acompanhante terapêutico de profissionais da saúde. $\mathrm{O}$ artigo de Amanda Candeloro Cunha, Danielle Abdel Massih Pio, Thaís Munholi Raccioni, intitulado "Acompanhamento Terapêutico: Concepções e Possibilidades em Serviços de Saúde Mental", analisou o conhecimento e percepções de equipes de saúde mental de um município do interior paulista acerca dessa temática, dentro da perspectiva da Clínica Ampliada e Reforma Psiquiátrica. Os autores indicam que a pesquisa possibilitou discutir acerca deste tema e da abertura de espaços para viabilizar a construção deste trabalho nos serviços, a qual consiste em uma potente estratégia para a reforma em saúde mental. O último destes três artigos, intitulado "Ideologia nas Opiniões 
de Estudantes de Ensino Médio sobre Sucesso no Trabalho", de João Wachelke, avaliou indicadores de opinião sobre sucesso no trabalho da Pesquisa de Percepções Sociais de Estudantes Uberlandenses em 2013. Os resultados deste estudo indicaram tendência de consenso na amostra a respeito da meritocracia como princípio vigente para garantir o sucesso no trabalho, bem como maior adesão dos estratos de renda e escolaridade inferiores a opiniões recomendando a obediência a chefes e normas de empresas.

Os cinco artigos que apresentam pesquisa sobre a área educacional tratam de temas bastante diferenciados sobre o trabalho da Psicologia neste campo da escola e da educação em geral. O primeiro destes artigos discute um tema bastante atual e debatido neste momento não somente no espaço da escola, mas da sociedade. O artigo "Manifestações de Bullying em Diferentes Contextos Escolares: um Estudo Exploratório", de Luís Gustavo Faria Aguiar e Sylvia Domingos Barrera, objetivou explorar a ocorrência de bullying em dois contextos escolares - público e privado -, com 76 alunos do Ensino Fundamental, comparando-as em termos de frequência e padrões de ocorrência do fenômeno. Os resultados indicaram que $24 \%$ dos participantes consideram-se vítimas de agressões repetidas, o que poderiam configurar episódios de bullying. Foi observada maior frequência de agressores do sexo masculino na escola pública, enquanto na particular não houve diferenças significativas quanto ao sexo dos agressores. Em ambas as escolas se encontrou elevada incidência de agressões, tanto nos recreios quanto em sala de aula, sendo a atitude passiva predominante entre os observadores. $\mathrm{O}$ segundo artigo de Alda Karoline Lima da Silva, Jorge Tarcísio da Rocha Falcão, Camila Costa Torres e Gimena Pérez Caraballo, intitulado "Os Impedimentos da Atividade de Trabalho do Professor na EAD", apresenta uma análise clínica dos impedimentos da atividade de trabalho do professor na Educação a Distância sob a ótica da abordagem da Clínica da Atividade. A análise da atividade de trabalho apontou diferentes formas de vivenciar os espaços de docência, como as mudanças que a EAD produziu na atividade dos professores que os convocaram a um acesso mais profundo das orientações genéricas da profissão, de modo a contribuir para revitalizações do fazer docente, diferenciados do modelo presencial como um guia, pois replicar o modelo presencial para EAD não seria garantia do sucesso da atividade do professor na EAD.
A produção acadêmica em Universidades brasileiras sobre Wilhelm Reich está vinculada a diferentes áreas, assim, o artigo de Sara Quenzer Matthiesen procurou identificar as dissertações de mestrado e teses de doutorado que têm explorado as ideias deste pensador e como tem sido articuladas à área educacional. O artigo "Sobre a Produção Acadêmica Reichiana Relacionada à Área Educacional”, a partir de uma pesquisa teórico-bibliográfica, localizou 39 produções acadêmicas entre 1979 e 2012 relacionadas a esta área, sendo 29 dissertações de mestrado e 10 teses de doutorado classificadas nas seguintes categorias: Ideias reichianas para a educação, Ideias reichianas e a educação de educadores, Ideias reichianas no cotidiano escolar, Ideias reichianas e a educação sexual e Aplicação das ideias reichianas em diferentes áreas da Educação.

O artigo de Inês Hennigen, Bruno Eduardo Procopiuk Walter e Guilherme Machado Paim também apresenta um tema bastante debatido na atualidade. $\mathrm{O}$ artigo intitulado "Consumo, Dinheiro e Diferenciações Sociais: Ditos de Jovens em uma Pesquisa Intervenção" objetivou abrir espaços de discussão e experimentações, e esboçar um quadro analítico sobre posicionamentos e vicissitudes na relação jovens/consumo. No processo de pesquisa emergiram questões como: estratégias dos jovens para obter dinheiro, diferenciação e status social a partir do consumo, e a internet enquanto necessidade de primeira ordem. Também abordando um tema bastante contemporâneo, o último artigo destes cinco relacionados a área da educação, intitulado "Modos de Ler Livros em Meios Digitais: Transformações da Experiência”, de Luciana Dadico, realizou uma pesquisa empírica cujo objetivo foi descobrir como leitores leem livros na tela digital através de entrevistas com quatro leitores adultos. A discussão aponta que os modos como os leitores liam livros na tela foram destacados e articulados às categorias imanentes do livro em tela, permitindo individuar padrões que participam da experiência de leitura, como a leitura flutuante, a leitura frenética e a leitura eficiente, ancoradas em elementos específicos da obra e empreendidas por um leitor utilitarista e receoso de aventurar-se em experiências novas.

A pesquisa teórica, nos diferentes campos do conhecimento, tem sido apresentada em modalidades que buscam contribuir para o aprofundamento de um tema ou conceito e são realizadas através do debate de teorias, da busca de bibliografias em base de dados para mapear o estado da arte de um deter- 
minado conhecimento, de revisões teóricas ou da busca de descritores utilizados na literatura para a compreensão de fenômenos. Assim, nesta edição da Revista "Psicologia: Ciência e Profissão", publicamos seis artigos dentro destas modalidades de pesquisa teórica. O primeiro deles, intitulado "O Legado Estruturalista em Lacan: Clínica e Diagnóstico da Psicose”, de Samira Pontes e Roberto Calazans, tem como objetivo apresentar algumas contribuições do estruturalismo à clínica lacaniana da psicose, tendo como chave de análise o chamado "diagnóstico estrutural". Para isso, realizou-se um breve retorno às principais contribuições do diálogo lacaniano com o estruturalismo na década de 1950 na busca de considerações fundamentais para enriquecer o debate e esclarecer se essa herança estruturalista na clínica das psicoses, apontando para importância das questões atuais que circunscrevem o campo diagnóstico para a abordagem do sofrimento psíquico.

Os próximos dois artigos dentro desta modalidade tratam do tema mulher, porém com focos e análises bem diferenciados. O primeiro deles, de Izabella Lenza Crema, Rafael De Tilio e Maria Teresa de Assis Campos, aborda a menopausa e as mudanças emocionais. Com o objetivo de apresentar uma revisão integrativa da literatura científica nacional e internacional sobre as possíveis repercussões da menopausa para a sexualidade de idosas, no artigo intitulado "Repercussões da Menopausa para a Sexualidade de Idosas: Revisão Integrativa da Literatura" foram analisadas 36 produções na íntegra cujo perfil predominante são estudos quantitativos, descritivos e transversais, desenvolvidos com mulheres de diferentes faixas etárias na pós-menopausa, incluindo idosas. A maioria das destas produções apontam para a importância da análise conjunta de aspectos biológicos, psicológicos, sociais, culturais e individuais para a compreensão das suas distintas influências na sexualidade das idosas. Já o segundo artigo traz como foco a violência com a mulher. "Violência contra a Mulher, Casas-abrigo e Redes Sociais: Revisão Sistemática da Literatura", de Scheila Krenkel e Carmen Leontina Ojeda Ocampo Moré, teve como objetivo caracterizar a produção científica de artigos empíricos sobre casas-abrigo e redes sociais no contexto da violência contra a mulher. Buscando artigos publicados entre 2004 e 2015, no Portal de Periódicos da Capes com os descritores utilizados foram shelter e social networks, combinados com violence against women e suas variações: domestic violence/gender vio- lence, foram encontrados 1.536 estudos encontrados. Os resultados mostraram aspectos positivos da passagem das mulheres pela casa-abrigo, como o apoio oferecido pelos profissionais, além de aspectos dificultadores após a saída do local, principalmente em relação à geração de trabalho e renda.

O quarto artigo que apresentamos nesta categoria de teóricos, com o título "Aliança Terapêutica nas Terapias Cognitivo-comportamentais por Videoconferência: uma Revisão da Literatura", de Bianca Aparecida Ribeiro Singulane e Laisa Marcorela Andreoli Sartes, trata intervenções por videoconferência. Este trabalho teve como objetivo realizar uma revisão de literatura acerca da formação e papel da aliança terapêutica nas terapias cognitivo-comportamentais por videoconferência através de uma busca em quatro bases de dados, Pubmed, Psycarticles, Lilacs e SciELO. foram encontrados 365 artigos, mas apenas nove preencheram os critérios de inclusão baseados no objetivo deste estudo, observando-se que a maioria dos artigos indicou que a aliança foi alta no decorrer das sessões de TCC por videoconferência, podendo ser comparada com a aliança formada na terapia presencial, e que poucos artigos avaliaram a aliança como fator preditivo de resultados e de adesão.

O artigo de Mário Lázaro Camargo, Edward Goulart Júnior e Lúcia Pereira Leite, intitulado "O Psicólogo e a Inclusão de Pessoas com Deficiência no Trabalho", discute a situação atual de pessoas com deficiência no mercado de trabalho, destacando os obstáculos e desafios presentes na realidade brasileira. Através de uma pesquisa bibliográfica realizada nas principais bases de dados disponíveis atualmente, apresentam o comprometimento com as transformações necessárias, tanto na sociedade quanto nas organizações de trabalho, para que tenhamos uma cultura verdadeiramente inclusiva. $\mathrm{O}$ estudo concluiu que ainda temos muito a avançar, considerando, sobretudo, as questões culturais que, somadas ao despreparo das organizações e dos gestores organizacionais para lidarem com os trabalhadores com deficiência, representam os maiores obstáculos à inclusão.

Com uma temática recente na literatura da área da Psicologia, o último artigo deste grupo de seis de estudos teóricos se reporta aos profissionais inseridos no âmbito das políticas públicas, nos chamados municípios de pequeno porte, marcados pela forte presença dos meios e povos rurais nos seus territórios. $\mathrm{O}$ artigo "Psicologia e Ruralidades no Brasil: Contri- 
buições para o Debate", de Kátya de Brito e Silva e João Paulo Macedo, através da localização da discussão da produção psicológica brasileira sobre rural e povos rurais, objetivou delinear as principais categorias teóricas e analíticas que possam contribuir para estabelecer um profícuo diálogo entre a Psicologia e os estudos rurais no Brasil. Evidenciou-se a importância de destacar a construção de um recorte crítico capaz de fortalecer a discussão acerca da presença da Psicologia no mundo rural para fortalecer seu lugar enquanto ciência e profissão, em meio a diferentes disciplinas que constituem os estudos rurais no Brasil.

Para fecharmos a edição 37.3 deste periódico, apresentamos o trabalho de Virgínia de Albuquerque
Mota e Ilze Maria Gonçalves da Costa, que trazem os desafios vivenciados na busca da efetivação da Reforma Psiquiátrica. Com o título "Relato de Experiência de uma Psicóloga em um Centro de Atenção Psicossocial", trata do relato da prática profissional de uma psicóloga em um Centro de Atenção Psicossocial em um município do interior do estado de Mato Grosso sobre sua formação profissional, com reflexões oriundas da prática junto aos usuários do serviço. As experiências de trabalho em um território deram origem à construção coletiva de um novo Projeto Terapêutico Global, com foco no sujeito de direitos e potencialidades, e a inserção de atividades preconizadas pela Política Nacional de Saúde Mental.

\section{Referências}

Bergson, H. (1974). Introdução à metafísica (Os Pensadores). São Paulo, SP: Abril Cultural.

Medeiros, P. F., \& Bernardes, A. G. (2005). O conceito de saúde e suas implicações nas práticas psicológicas. Psicologia. Teoria e Pesquisa, 21(3): 263-269. https://doi.org/10.1590/S0102-37722005000300002

Rose, N. (2008). Psicologia como uma ciência social. Psicologia \& Sociedade, 20(2), 115-164. https://doi.org/10.1590/S0102-71822008000200002

Scisleski, A. (2010). Governando a vida: (pro)vocações para a psicologia. In N. Guareschi, A. Scisleski, C Reis, G. Dhein, \& M. A. Azambuja (Org.), Psicologia, formação, políticas e produção em saúde (v. 1, pp. 167-183). Porto Alegre, RS: EdiPUCRS.

\section{Neuza Maria de Fátima Guareschi}

Universidade Federal do Rio Grande do Sul

Editora

Email: neuza.guareschi@cfp.org.br

Como citar: Guareschi, N. M. F. (2017). Práticas da Psicologia no Campo da Justiça, do Trabalho e da Educação, 37(3), 548-552. https://doi.org/10.1590/1982-3703200002017

How to cite: Guareschi, N. M. F. (2017). Practices of Psychology in the Felds of Justice, Work and Education. Psicologia: Ciência e Profissão, 37(3), 548-552. https://doi.org/10.1590/1982-3703200002017

Cómo citar: Guareschi, N. M. F. (2017). Prácticas de la Psicología en el Campo de la Justicia, Trabajo y Educación. Psicologia: Ciência e Profissão, 37(3), 548-552. https://doi.org/10.1590/1982-3703200002017 